\title{
Correction to: The weakness of weak ties for novel information diffusion
}

\author{
Jennifer M. Larson
}

\author{
Correspondence: jenn.larson@nyu. \\ edu \\ The original article can be found \\ online at https://doi.org/10.1007/ \\ s41109-017-0034-3 \\ New York University, Department of \\ Politics, 19 W. 4th St., New York, NY \\ 10012, USA
}

\author{
Correction to: Appl Netw Sci (2017) 2: 14 \\ https://doi.org/10.1007/s41109-017-0034-3
}

Following publication of the original article (Larson Applied Network Science 2017), the author reported to publish a brief corrigendum in the original article;

Corrigendum to "The Weakness of Weak Ties for Novel

Information Diffusion"

Jennifer M. Larson

January 4, 2020

In Larson (2017), I erroneously implied that it was the first article to formally account for the lower capacity of weak ties for information transmission. Unbeknownst to me, Aral and Van Alstyne (2011) did so previously. Aral and Van Alstyne (2011) begins with the same premise that weak ties would likely transmit information less well and less often, and also develops a model to examine when and to what extent weak ties may be impediments to the spread of information. In multidisciplinary research areas such as network science, the onus is on the researcher to search broadly for related work and give due credit.

In Aral and Van Alstyne (2011), the authors consider a context of distributed knowledge and consider whether weak ties are best for accessing a diverse set of information quickly. They find that because strong ties transmit so much more information, under reasonable conditions weak ties are in fact not best for quick access to a diverse portfolio of information. I take up a different information environment, one meant to capture a situation in which brand new, unexpected news becomes available and can be shared or withheld at the discretion of those who learn it. My focus is on the reach of new news, not the diversity of information that a person can acquire. I account for the lower capacity of weak ties (as in Aral and Van Alstyne (2011)) and also the limited opportunities that a person may have to communicate with her social contacts. The latter starkly differentiates the two models and generates the surprising result that even adding weak ties to a given network without deleting or replacing ties can strictly reduce the extent of information diffusion.

The novelty of this article is not in the suggestion that weak ties transmit information less well than strong ties, but in the particular set of assumptions that accounts for this quality in a supplydriven information enviornment, and in identifying the

(c) The Author(s). 2020 Open Access This article is distributed under the terms of the Creative Commons Attribution 4.0 International License (http://creativecommons.org/licenses/by/4.0/), which permits unrestricted use, distribution, and reproduction in any medium, provided you give appropriate credit to the original author(s) and the source, provide a link to the Creative Commons license, and indicate if changes were made. 
conditions under which adding new, weak ties to the ties already in a network (and so increasing the total number of ties) makes information transmission strictly worse.

\section{References}

Aral, Sinan and Marshall Van Alstyne. 2011. "The diversity-bandwidth trade-off." American Journal of Sociology 117(1):90-171

Larson, Jennifer M. 2017. "The weakness of weak ties for novel information diffusion." Applied network science 2(1):14

Published online: 30 January 2020

\section{Reference}

Larson Applied Network Science (2017) The weakness of weak ties for novel information diffusion. Appl Netw Sci 2(1):14. https://doi.org/10.1007/s41109-017-0034-3 